\title{
Progranulin derived engineered protein Atsttrin suppresses TNF- $\alpha$-mediated inflammation in intervertebral disc degenerative disease
}

\author{
Hong Ding ${ }^{1, *}, J_{i a n l u ~ W e i}{ }^{1, *}$, Yunpeng Zhao $^{1}$, Yi Liu ${ }^{1}$, Lian Liu ${ }^{1}$ and Lei Cheng ${ }^{1}$ \\ ${ }^{1}$ Department of Orthopaedics, Qilu Hospital of Shandong University, Jinan, China \\ *These authors have contributed equally to this work \\ Correspondence to: Lei Cheng, email: chengleiyx@126.com \\ Keywords: Atsttrin; TNF- $\alpha$; progranulin; intervertebral disc degeneration; inflammation \\ Received: September 06, $2017 \quad$ Accepted: October 29, $2017 \quad$ Published: November 29, 2017 \\ Copyright: Ding et al. This is an open-access article distributed under the terms of the Creative Commons Attribution License 3.0 \\ (CC BY 3.0), which permits unrestricted use, distribution, and reproduction in any medium, provided the original author and source \\ are credited.
}

\section{ABSTRACT}

Atsttrin, an engineered molecule composed of three fragments of progranulin(PGRN), exerts comparable anti-inflammation ability. Intervertebral disc degeneration (IDD) is involved in inflammation in which TNF-a plays a key role. This study aims to examine the effect and the mechanism of Atstrin in the pathogenesis of intervertebral disc degeneration. For this purpose, we took advantage of murine and human intervertebral disc (IVD) and examined the expression of TNF-a in IVD tissues using immunohistochemistry and TNF-a level in peripheral sera by ELISA assay. Moreover, murine IVD was taken to undergo the Safranin 0 and HE staining. Furthermore, primary human nucleus pulposus cells were used for immunohistochemistry staining, fluorescent staining, Western Blot, ELISA assay and RT-PCR assay. Herein we found TNF-a expression was elevated in intervertebral disc and peripheral sera in patients with IDD. Interestingly, Atsttrin effectively inhibited TNF-a-mediated catabolism in murine disc by ex vivo study. TNF-a-induced inflammatory cytokines were strongly reduced in presence of Atsttrin in primary human disc. Mechanism study indicated Atsttrin protected against intervertebral disc degeneration by inhibiting TNF-a-induced inflammation. These findings show that Atsttrin is a potential molecular target for disc degenerative diseases.

\section{INTRODUCTION}

Intervertebral disc degeneration(IDD) is an irreversible degenerative disease which is very common in the elderly, characterized by disc inflammation, endplate degeneration, vertebral osteophyte formation, spinal canal stenosis $[1,2]$. The clinical manifestation of IDD include low back pain, radiating ache in lower extremity, numbness and weak of low limb [3], strongly affect the patient's daily life. So far there has no drugs and effective treatment can reverse the pathogenesis of intervertebral disc degeneration, and surgery is the final treatment for these diseases.

Tumor necrosis factor- $\alpha$ (TNF- $\alpha$ ) plays an important role in the process of intervertebral disc degeneration, and it also be the key reason for the low back pain $[4,5]$. Serum level of TNF- $\alpha$ is relative to the pain threshold in IDD patients [6]. TNF- $\alpha$ stay at the peak of the inflammatory cascade response [7, 8]. Even slight change of TNF- $\alpha$ causes great changes of the downstream inflammatory factor such as IL-1 $\beta$, MMP-13 and iNOS. Targeting TNF $\alpha$ pathways has been proven to be highly successful for treatment of many autoimmune diseases $[2,3]$.

Progranulin, which is also known as PGRN, is a growth factor which has a unique structure with "beedson-a-string". PGRN is expressed in various cells and plays a critical role in various physiological and pathological processes, including wound healing, tumorigenesis and inflammation [9-11]. Atsttrin (antagonist of TNF-TNFR 
signaling via targeting to TNFR) is an engineered protein derived from PGRN, which is constituted of half-units of granulins A, C, and F plus linkers P3, P4, and P5 [12]. Studies indicated the engineered protein Atsttrin has similar functions with PGRN in many physiological processes. Additionally, Atsttrin has some advantages over PGRN such as longer half-life, higher efficacy, lower molecular weight and no oncogenic effects [13]. Recently, studies indicated Atsttrin exhibited protective effect in several diseases. Specifically, Atsttrin was reported to have therapeutic effect in inflammatory arthritis [12, 13]. Furthermore, Atsttrin exhibited therapeutic effect in inflammatory bowel disease [14]. Moreover, Atsttrin exerts protective effect in bone healing and degenerative osteoarthritis through inhibiting TNF- $\alpha$ signaling [15]

Given the indication that previous study demonstrated that loss-of-PGRN accelerated degeneration in the aging mice model and the importance of Atsttrin's anti-inflammation ability, in this study, we determined to examine whether Atsttrin as PGRN-derived engineered molecule, has a protective effect in intervertebral disc degeneration as well as the molecular mechanism involved.

\section{RESULTS}

\section{TNF- $\alpha$ is increased in degenerative IVD and peripheral serum}

\begin{abstract}
To investigate expression of TNF- $\alpha$ in the pathogenesis of IDD, we performed immunohistochemistry staining in IVD tissues from normal people and patients with IDD respectively. As shown in Figure 1A \& 1B, TNF- $\alpha$ expression in disc of IDD was remarkably increased compared to normal group (IDD group increased $310 \%$ compared with normal group, Figure 1C). Furthermore, to determine the level of TNF- $\alpha$ in peripheral blood of the normal people and the people with IDD, the serum were collected and ELISA assay was performed. As demonstrated in Figure 1D, TNF- $\alpha$ level was significantly up-regulated in IDD patients. Taken together, TNF- $\alpha$ is increased in the pathogenesis of IDD.
\end{abstract}

\section{Atsttrin exhibited therapeutic effect in murine disc ex vivo}

Given the finding that TNF- $\alpha$ is increased in the pathogenesis of IDD and the importance of TNF- $\alpha$ in IDD process, to further determine whether Atsttrin could suppress TNF- $\alpha$-mediated catabolism in disc, we isolated murine disc and did ex vivo study. For this purpose, we cultured the mice disc with or without $50 \mathrm{ng} / \mathrm{ml} \mathrm{TNF}-\alpha$ in the presence or absence of $1 \mathrm{ug} / \mathrm{ml}$ Atsttrin for 7 days. Followed by Safranin O staining and HE staining. As is shown in Figure 2A, TNF- $\alpha$ strongly induced cartilage loss while in the presence of Atsttrin remarkably restored cartilage in the endplates and NP of the disc. Furthermore, statistical analysis indicated cartilage significantly decreased in the nucleus area (Figure 2B). However, Atsttrin effectively inhibited TNF- $\alpha$-induced nucleus catabolic metabolism. We also performed HE staining, as is shown in Figure 2C, TNF- $\alpha$ accelerated the loss of the disc height and nucleus pulposus cells in IVD, while co-cultured with Atsttrin alleviated this structural degeneration. The result suggested that Atsttrin attenuated TNF- $\alpha$-mediated catabolism.

\section{Atsttrin reduced TNF- $\alpha$-induced inflammatory cytokines in human nucleus}

To further determine the mechanism of Atsttrin in the process of IDD, we took advantage of primary human intervertebral disc tissues in the ex vivo study. It's widely accepted that TNF- $\alpha$ plays a critical role in the intervertebral disc degeneration process. In addition, TNF- $\alpha$-induced inflammatory cytokine such as IL-17, IL-1, COX-2 and iNOS could cause further destruction. To investigate whether Atsttrin could inhibit TNF- $\alpha$ induced inflammation in human disc, we cultured the nucleus tissues with or without TNF- $\alpha$ in presence or absence of Atsttrin for 7 days. After harvested the tissues, immunohistochemistry staining was performed for the expression of MMP-13, COX-2, iNOS and IL17, As is illustrated in Figure 3A, expression of MMP13 , COX-2, iNOS and IL-17 were highly elevated in presence of TNF- $\alpha$ which is in line with previous studies. Furthermore, as demonstrated in Figure 3B-3E, statistical analysis of the immune-staining intensity indicated that TNF- $\alpha$ significantly elevated expression of MMP-13, COX-2, iNOS and IL-17 up to $299 \%, 207 \%, 389 \%$ and $225 \%$, respectively. However, as shown in Figure 3A, Atsttrin effectively reduced TNF- $\alpha$-induced inflammatory cytokines in human disc. Specifically, expression of MMP-13, COX-2, iNOS and IL-17 was decreased about $62 \%, 42 \% 56 \%$ and $50 \%$, respectively (Figure 3B-3E). To further confirm our findings, we isolated primary human nucleus cells and cultured with or without TNF- $\alpha$ in presence or absence of Atsttrin for 2 days. After 2 days' incubation, we harvested and fixed the cells, followed by immunofluorescent staining. As indicated in Figure $4 \mathrm{~A} \& 4 \mathrm{C}$, the expression of inflammatory cytokines, including COX-2 and iNOS were remarkably up-regulated after TNF- $\alpha$ treatment in the primary human nucleus cells. However, additional use of recombinant Atsttrin effectively reduced the expression of these molecules. Statistical analysis showed Atsttrin inhibited TNF- $\alpha$ induced inflammatory cytokines in vitro (Figure 4B \& 4D). Above all, Atsttrin alleviated TNF- $\alpha$-mediated inflammation by reducing expression of TNF- $\alpha$-induced downstream molecules. 


\section{Atsttrin protects against IDD via inhibiting TNF- $\alpha$ signaling}

Given the finding that Atsttrin has a therapeutic effect in IDD process and the importance of Atsttrin's anti-TNF- $\alpha$ capacity, we next determined the mechanism of Atsttrin in the pathogenesis of IDD. To address this issue, we harvested the nucleus cells from human lumbar intervertebral disc and cultured the cells with $10 \mathrm{ng} / \mathrm{mL}$ TNF- $\alpha$ in presence or absence of $200 \mathrm{ng} / \mathrm{mL}$ Atsttrin for 6 hours. Then the total RNA was extracted and followed by Real-time PCR assay. As indicated in Figure 5A-5C, the transcriptional levels of MMP-13, COX-2 and iNOS were significantly increased in TNF- $\alpha$ treated group compared to the control group. While Atsttrin significantly reduced the transcriptional level of these molecules. Besides RNA transcription, we next analyzed the protein expression. In detail, we cultured the primary human nucleus cells with $10 \mathrm{ng} / \mathrm{mL}$ TNF- $\alpha$ in presence or absence of different concentrations of Atsttrin $(0,20,50,100,200 \mathrm{ng} / \mathrm{ml})$ for 48 hours. Supernatant and cells were collected. Total protein was extracted from cells and western blot was performed for COX-2, MMP-13 and iNOS. As revealed in the Figure 5D, Atsttrin inhibited TNF- $\alpha$ induction of COX-2, MMP-13 and iNOS in a dose-dependent manner (Figure 5E-5G). Moreover, as is shown in Figure 5H, the level of IL- 6 in the supernatant is elevated in TNF- $\alpha$ treated group comparison with control group while Atsttrin could inhibited the TNF- $\alpha$ 's effect in a concentrationdependent manner. Collectively, Atsttrin protects against IDD through inhibiting TNF- $\alpha$ pathway.

\section{DISCUSSION}

Intervertebral disc degeneration (IDD) is one of the most popular degenerative diseases which highly affect people's daily life [2]. So far, only symptom release or modified drugs are available. However, no

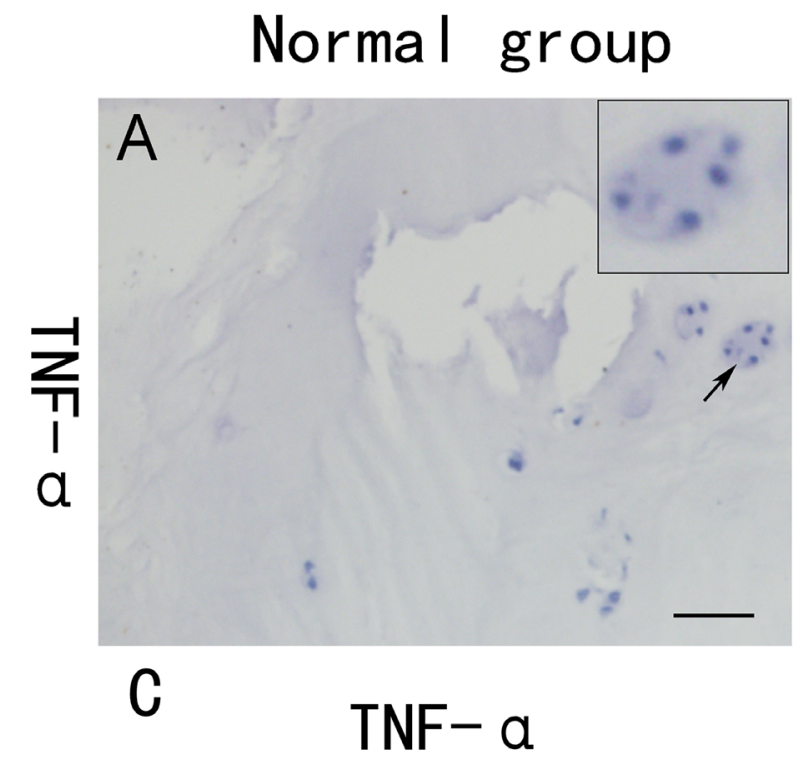

IDD group
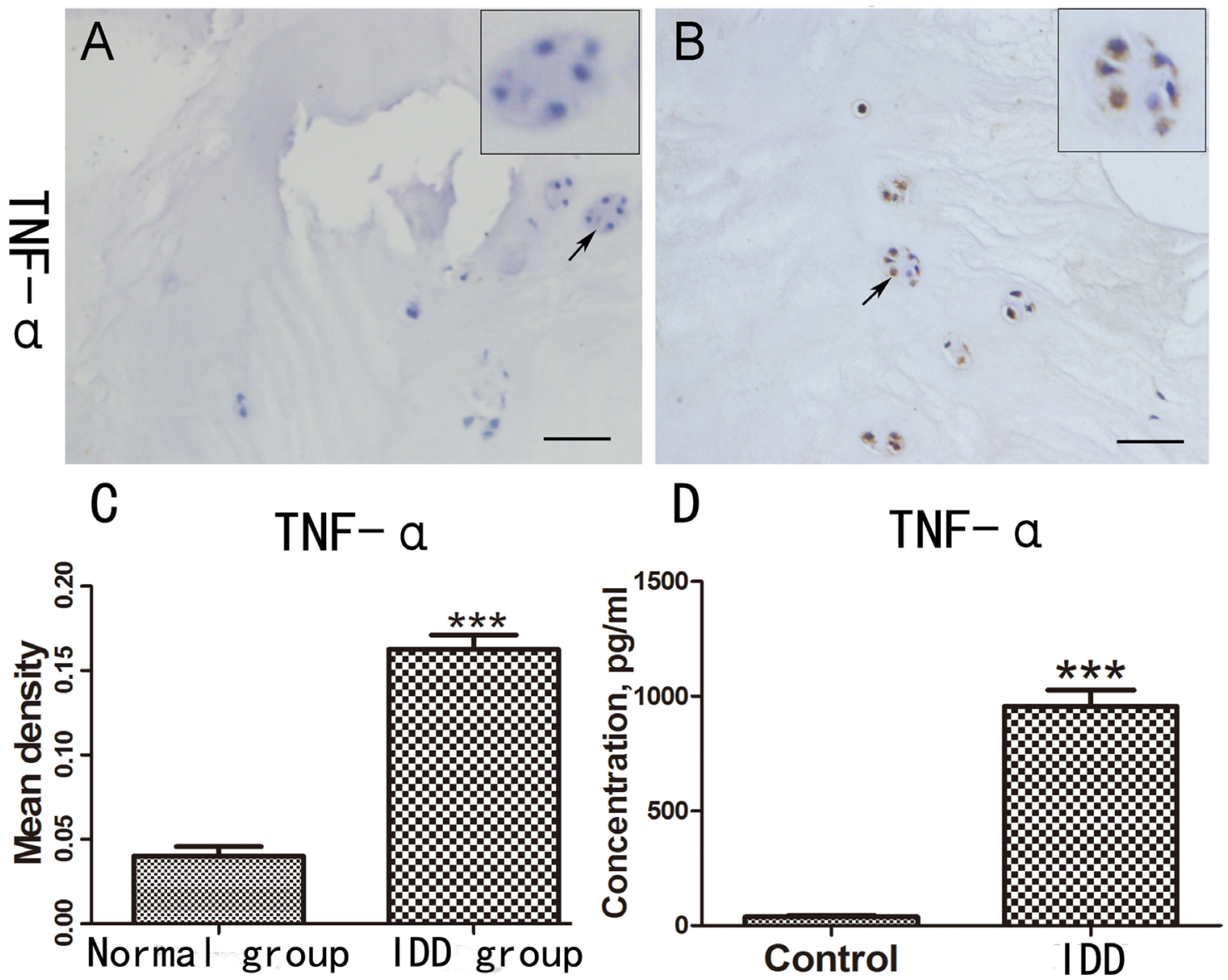

Figure 1: TNF- $\alpha$ is increased in degenerative IVD and peripheral serum. (A-B) Expression of TNF- $\alpha$ in the IVD tissues of normal people and patients with IDD was detected by the immunohistochemical staining. (C) Mean density of the normal group and IDD group based on the result of immunohistochemical staining. (D) The different serum level of TNF- $\alpha$ in the normal people (N=10) and the patients with IDD $(\mathrm{N}=40)$, Scale bar=100 um. The values are mean $\pm \mathrm{SEM}$ of at least 3 independent experiments; ${ }^{* * *} \mathrm{P}<0.001$. 


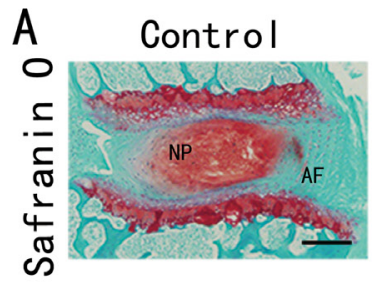

C Control

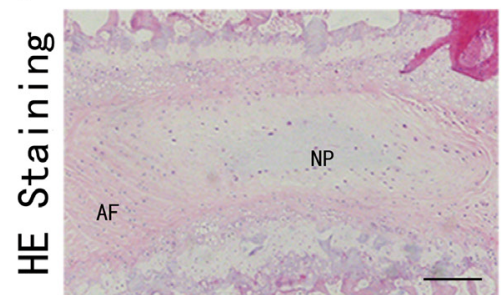

TNF- a
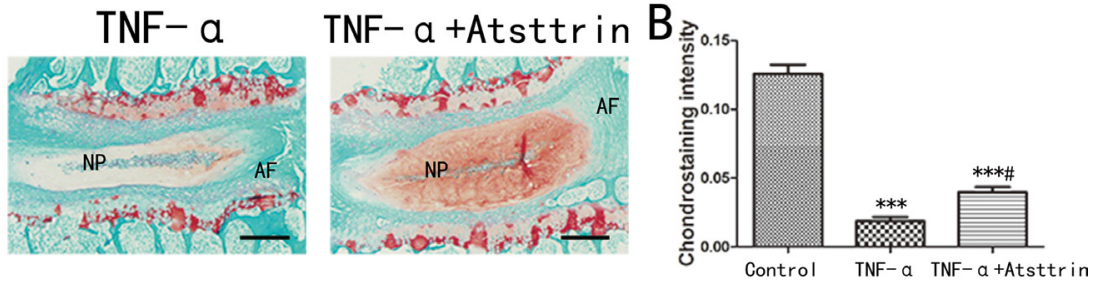

TNF- a

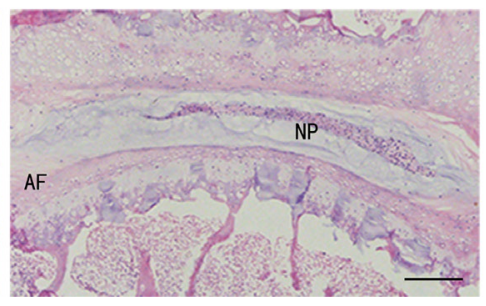

TNF- a +Atsttrin

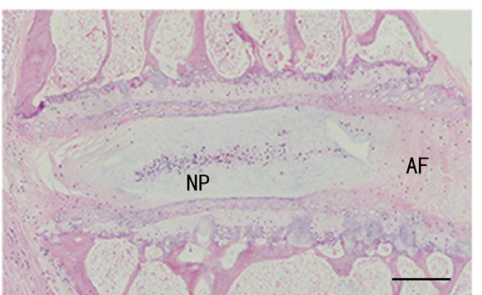

Figure 2: Atsttrin exhibited therapeutic effect in murine disc ex vivo. (A) After culture the mouse IVD with TNF- $\alpha$ (50 $\mathrm{ng} / \mathrm{ml}$ ) in the presence or absence of Atsttrin $(1 \mathrm{ug} / \mathrm{ml})$ respectively and Safranin O staining was performed. (B) Chondrostaining density analysis shown Atsttrin attenuated the loss of cartilage tissue in IVD induced by TNF- $\alpha$. (C) After culture the mouse IVD with TNF- $\alpha$ (50 ng/ml) in the presence or absence of Atsttrin $(1 \mathrm{ug} / \mathrm{ml})$ respectively and HE staining was performed. TNF- $\alpha$ accelerated the loss of the height and nucleus pulposus in IVD, while co-cultured with Atsttrin alleviated this structural degeneration. Abbreviation: NP: nucleus pulposus; AF: annulus fibrosus. Scale bar $=200 \mathrm{um}$. The values are mean $\pm \mathrm{SEM}$ of at least 3 independent experiments; ${ }^{* * *} \mathrm{P}<0.001 \mathrm{VS}$ control group, ${ }^{\#} \mathrm{P}<0.05$ VS TNF- $\alpha$ treatment group.

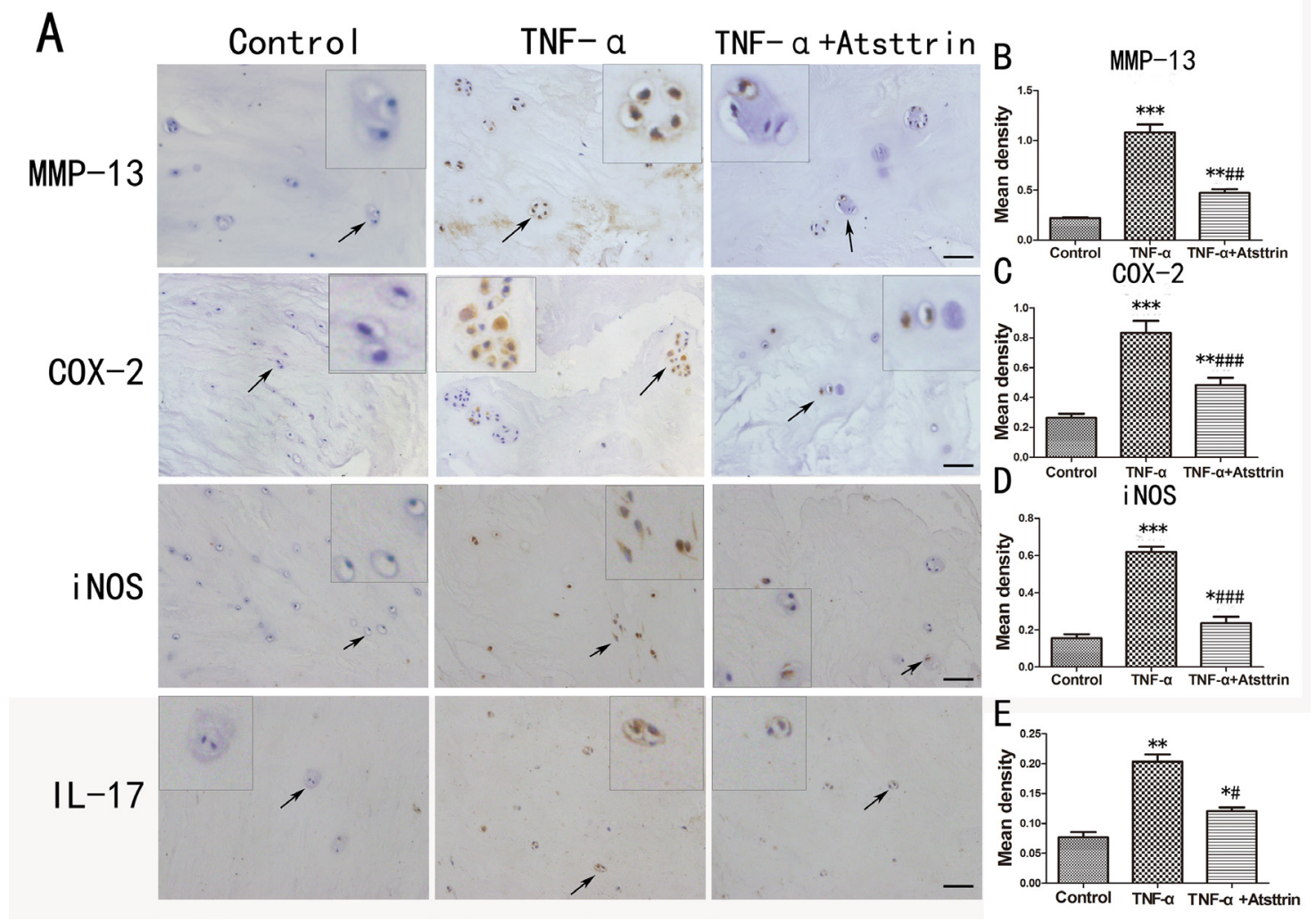

Figure 3: Atsttrin reduced TNF- $\alpha$-induced inflammatory cytokines in human nucleus. (A) The immunohistochemistry of MMP-13, COX-2, iNOS and IL-17 in the human IVD tissues cultured TNF- $\alpha(50 \mathrm{ng} / \mathrm{ml})$ in the presence or absence of Atsttrin (1 ug/ml) respectively. Scale bars=100 um. (B, C, D, E) Quantitative analysis of the positive area of MMP-13, COX-2, iNOS and IL-17 in different groups based on the result of immunohistochemical staining. The values are mean $\pm \mathrm{SEM}$ of at least 3 independent experiments, ${ }^{*} \mathrm{P}<0.05$, ${ }^{* *} \mathrm{P}<0.01,{ }^{* * *} \mathrm{P}<0.001$ VS control group. ${ }^{\#} \mathrm{P}<0.05,{ }^{\# \#} \mathrm{P}<0.01,{ }^{\# \# \#} \mathrm{P}<0.001$ VS TNF- $\alpha$ treatment group. 
drugs are commercial available to cure this disease. The final outcome usually is surgery. Unfortunately, surgery accompany with high cost and uncertain complication. So clinically it's very urgent and helpful for discovering a new alternative for treating IDD.

It's widely accepted that inflammation plays a critical role in the pathogenesis of IDD $[16,17]$. In the process, the inflammatory cytokines, such as TNF- $\alpha$, IL1, IL-17, COX-2 and iNOS are significantly increased in IDD patients [18-20]. The inflammatory molecules mediate inflammation and cause disc destruction [18, 21]. Moreover, the inflammatory molecules induce inflammatory cascade and destroy the matrix of the disc, further mass the disc. Nowadays, more and more studies focused on the anti-inflammation in IDD and achieved excited indications $[22,23]$.
Among these molecules, TNF- $\alpha$ attract researchers' attention owing to its peak site of the inflammatory cascade $[8,24]$. Previous studies indicated that TNF- $\alpha$ could accelerate intervertebral disc degeneration, promote adjacent bone absorb and enhance endplate degeneration $[21,25]$. Furthermore, evidence showed that TNF- $\alpha$ is the base of inflammation in IDD process [26]. Clinical study showed that the level of TNF- $\alpha$ was related to low back pain in patients $[4,27,28]$. Higher TNF- $\alpha$ level indicated suffering more pain. Additionally, anti-TNF- $\alpha$ drugs exhibited a therapeutic effect in IDD process [29]. Mechanism study revealed TNF- $\alpha$ mess the disc through at least two ways. A) directly induce downstream inflammatory molecules, including IL-17, IL-6, to cause and enhance the local and systemic inflammation. B) mediate the expression of matrix metalloproteinase,
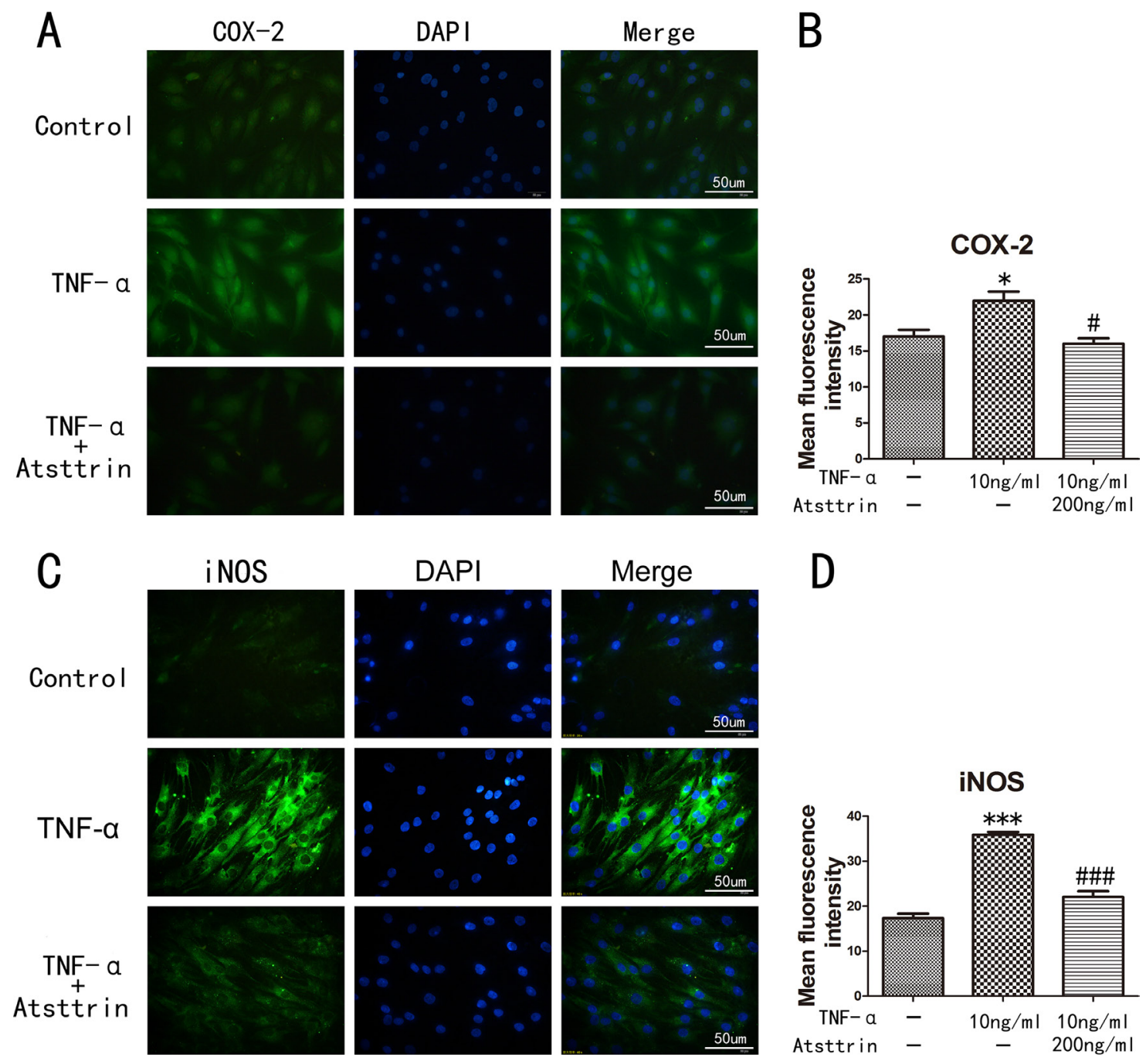

Figure 4: Inflammatory cytokines in human nucleus cells detected by immunofluorescent staining. (A, C) Expression of iNOS and COX-2 in human NP cells detected by the immunofluorescence. (B, D) Analysis of the mean fluorescence intensity of COX-2 and iNOS according to the result of immunofluorescence results. The NP cells was treated with TNF- $\alpha(10 \mathrm{ng} / \mathrm{ml})$ in the presence or absence of Atsttrin (200 ng/ml), scal bars $=50$ um. ${ }^{*} \mathrm{P}<0.05,{ }^{* * *} \mathrm{P}<0.001$, VS control group. ${ }^{\#} \mathrm{P}<0.05,{ }^{\# \#} \mathrm{P}<0.001$, VS TNF- $\alpha$ treatment group. 
disable the stability of the disc construction. We previously reported that TNF- $\alpha$ promoted CCL 20 recruit TH17 cells in nucleus cells, causing increased secretion of IL-17 [30]. In addition, IL-17 mediated inflammation in nucleus cells through JNK/c-Jun signaling [31]. Collectively, given the importance of TNF- $\alpha$ in regulating of IDD, it's of high innovation for discovering a new alternative medicine which targeting TNF- $\alpha$ pathway in IDD pathogenesis.

Progranulin, also known as PGRN, is a growth factor with potent anti-inflammation ability. PGRN consists of seven and half units (P-G-F-B-A-C-E-D) [32]. While $\mathrm{P}$ is a half unit and others are full unit. The unit is called granulin(GRN). Interesting, PGRN is considered as anti-inflammation factor while GRN is thought as proinflammation factor [33]. It's well known that PGRN effectively interfere TNF- $\alpha$ signaling by completely binding to the TNF- $\alpha$ receptors (TNFRs) $[12,34]$. On the basis of PGRN's unique structure, Tang et al discovered an engineered protein which is named Atsttrin [12]. Atsttrin consists of half unit of F-A-C and their linkers (1/2F-1/2A-
1/2C) $[12,35,36]$. Similar to PGRN, Atsttrin retains the binding affinity with TNFRs [37]. However, Atsttrin has some advantages over PGRN such as longer half-life, higher efficacy, lower molecular weight and no oncogenic effects [13]. These specific advantages imply Atsttrin may have more insights in dealing with inflammatory diseases.

Previous study indicated that Atsttrin had a therapeutic effect in the inflammatory arthritis mice model in which TNF- $\alpha$ plays a predominant role [12-14]. In addition, Atsttrin effectively inhibited TNF- $\alpha$-induced osteoclastogenesis. Furthermore, in bone healing process, Atsttrin exerted a therapeutic effect by interfering with TNF- $\alpha$ signaling [38]. Recent study indicated Atsttrin was an alternative for the treatment of inflammatory bowel disease in the mice model [14]. Despite the anti-catabolic ability, it's reported that overexpression of Atsttrin promoted cartilage repair [13]. Given the importance of TNF- $\alpha$ in IDD process and Atsttrin's potent antiinflammatory ability, we determined the role of Atsttrin in IDD.

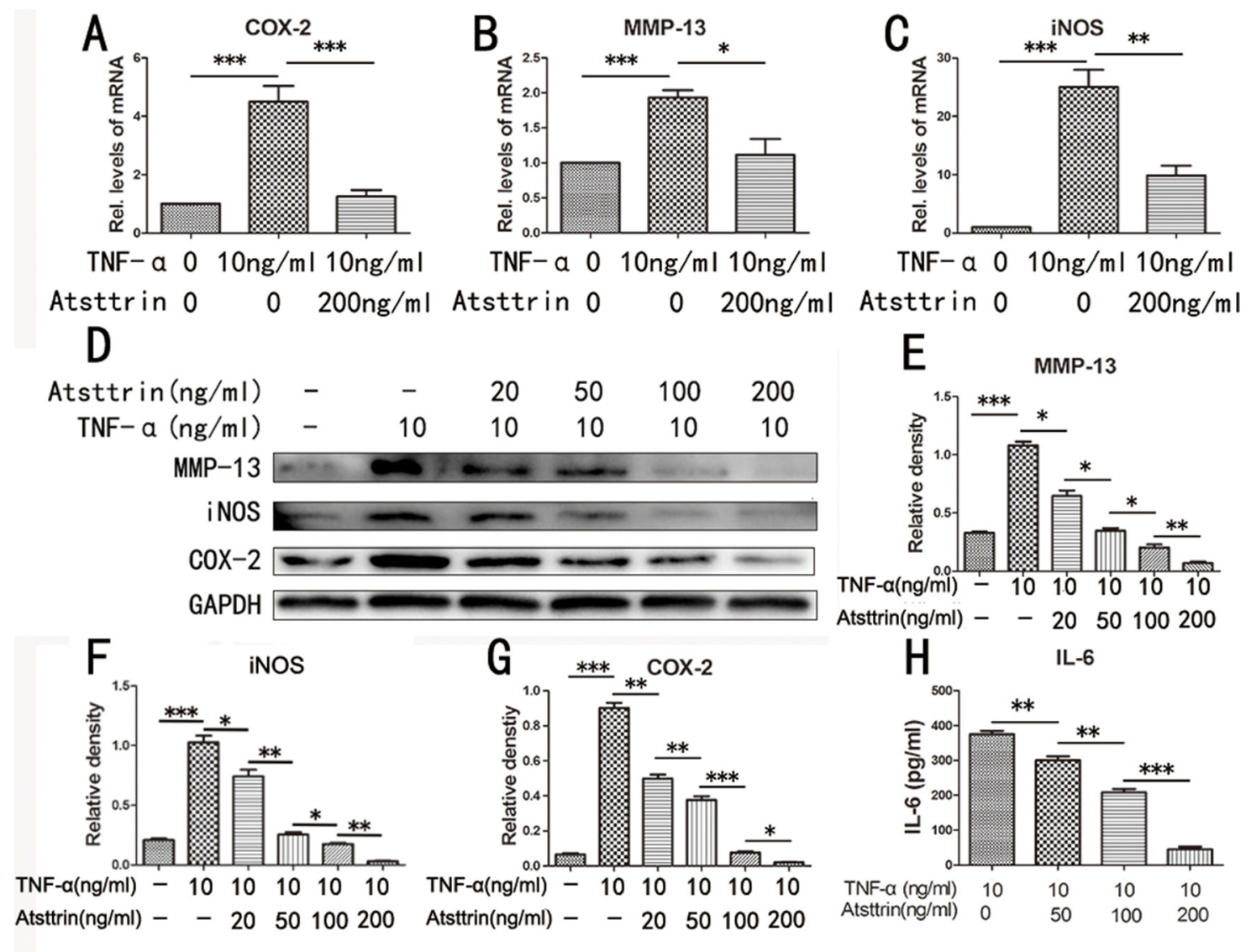

Figure 5: Atsttrin protects against IDD via inhibiting TNF- $\alpha$ signaling. (A, B, C) MMP-13, iNOS and COX-2 mRNA expression level was detected by RT-PCR, the mRNA expression of MMP-13, iNOS and COX-2 was significant increase in the TNF- $\alpha$ $(10 \mathrm{ng} / \mathrm{ml})$ treatment group compared with control group, after co-culture with Atsttrin $(200 \mathrm{ng} / \mathrm{ml})$, these molecules' transcriptional level were significantly reduce. (D) The protein level of MMP-13, COX-2 and iNOS in the human nucleus pulposus cells which co-culture with TNF- $\alpha$ in the presence or absence of different concentration of Atsttrin $(20,50,100,200 \mathrm{ng} / \mathrm{ml})$. (E, F, G) Mean density of immunoblot of MMP-13, COX-2 and iNOS at different concentration of Atsttrin. (H) Secretion of IL-6 in different groups detected by ELISA. The values are mean \pm SEM of at least 3 independent experiments, ${ }^{*} \mathrm{P}<0.05,{ }^{* *} \mathrm{P}<0.01,{ }^{* * *} \mathrm{P}<0.001$. 
Table 1: Real-time PCR primers

\begin{tabular}{lcc}
\hline Target & Forward primers, $\mathbf{5}^{\prime}-\mathbf{3}^{\prime}$ & Reverse primers, $\mathbf{5}^{\prime}-\mathbf{3}^{\prime}$ \\
\hline COX-2 & TCAGCCATACAGCAAATCCTTG & GTCCGGGTACAATCGCGACTT \\
MMP-13 & CATGAGTTCGGGCCACTCCTT & CCTGGACCATAGAGAGACTGGA \\
iNOS & CGTGGAGACGGGAAAGAAGT & FACCCCAGGCAAGATTTGGA \\
GAPDH & GCACCGTCAAGGCTGAGAAC & TGGTGAAGACGCCAGTGGA \\
\hline
\end{tabular}

Abbreviations: MMP13: matrix metalloprotease 13; COX-2: cyclooxygenase-2; iNOS: inducible nitric oxide synthase.

In the present study, we found TNF- $\alpha$ was upregulated in local nucleus cells and peripheral blood $[28,39]$. This finding is in line with previous studies. To test the role of Atsttrin in IDD process, we performed ex vivo study by using murine intervertebral disc. Herein, we found additional use of TNF- $\alpha$ accelerated cartilaginous tissue loss in the murine intervertebral disc. Additionally, TNF- $\alpha$ indeed affected the construction of intervertebral disc, however, in present study we did not see the osteophyte formation which may due to the less duration of treatment or the different microenvironments between ex vivo and in vivo. Intervertebral disc is full of matrix (aggrecan and collagen II)), in the pathogenesis of IDD, inflammatory cytokines penetrated and cause destruction. Metalloproteinase 13 (MMP-13) is the main enzyme which digesting type II collagen (Col II) [40], causing matrix distortion. We found TNF- $\alpha$ indeed increased the expression of MMP-13 in the human nucleus tissues, while additional use of recombinant Atsttrin strongly reduced MMP-13's expression, slowing down the matrix destruction. Furthermore, it's well known that TNF- $\alpha$ directly induce iNOS and COX-2, and they are regarded as the severity maker as inflammation [41]. We confirmed this finding in the human nucleus tissues and interestingly we found Atsttrin effectively inhibited these inflammatory molecules. Besides the ex vivo study, we confirmed our findings by in vitro assay. Fluorescent staining indicated in the human nucleus cells, TNF- $\alpha$ remarkably increased the expression of iNOS and COX-2, however, iNOS and COX-2's expressions were significantly decreased in presence of Atsttrin. Given the findings that recombinant Atsttrin has a potential therapeutic effect in the intervertebral disc degeneration, and the clue that Atsttrin exerted a protective effect via targeting TNF- $\alpha$ pathway in the inflammatory arthritis mice model, we next determined that Atsttrin inhibited this pathogenesis through interfering with TNF- $\alpha$ signaling. In present study, we took advantage of primary human nucleus cells and mimic in vivo stimulation. We found Atsttrin significantly down-regulated TNF- $\alpha$-induced inflammatory cytokines' expression at transcriptional level. Sequentially, the protein expressions of inflammatory molecules were dramatically reduced. Collectively, Atsttrin has a therapeutic effect in IDD, and this effect is through inhibiting TNF- $\alpha$ signaling.

Atsttrin is a new engineered molecule derived from the growth factor PGRN. Nowadays, more and more studies indicated Atsttrin exhibited a strong antiinflammation ability and exerted a protective effect in some pathological processes. It's reported Atsttrin was therapeutic in inflammatory arthritis mice model; moreover, overexpression of Atsttrin in local articular cartilage protected against osteoarthritis [13, 36]; and study showed that Atsttrin promoted bone healing through inhibiting TNF- $\alpha$ pathway in the physiological process. All these previous studies demonstrated that Atsttrin could be a drug candidate for the inflammatory disease in which TNF- $\alpha$ plays a predominate role. And indeed, in our present study, we found Atsttrin exerted a protective effect through, at least partially through inhibiting TNF- $\alpha$ signaling.

Collectively, Atsttrin is therapeutic in the intervertebral disc degenerative disease via targeting TNF- $\alpha$ and Atsttrin could be a noval drug candidate for the inflammatory degenerative diseases.

\section{MATERIALS AND METHODS}

\section{Ethics statement}

40 patients with single level lumbar disc herniation were enrolled between 2017.1.1 and 2017.5.31 at Qilu Hospital of Shandong University. Collection of lumbar disc tissue and peripheral blood samples was performed according to the medical ethics regulations of Medical Ethical Committee of Qilu Hospital of Shandong University. This research was approved by the Qilu Hospital of Shandong University Review Board, and written informed consent document was requested and received from all patients and healthy individuals in the study. The animal experimental procedures were performed with the formal approval of The International Guiding Principles for Animal Research, as approved by the Laboratory Animal Centre of Shandong University. 


\section{Patients}

All the patients enrolled in this study signed the informed consent and agreed to participate in this study, 40 patients with lumber disc herniation (LDH) (37-61 years; mean $51.63 \pm 9.12$ years) were enrolled in our study as the experimental group. The selection criteria were as follows: 1) persistent lumbosacral pain accompanied with lower limb radiating pain at least 3 months ,accompanied by or without limb numbness; 2) lumber disc MRI and CT imaging studies showed significant disc herniation performance and compression of the nerve; 3) Lasegue's sign $(+)$ or positive for femoral nerve traction test $(+)$. The exclusion criteria were as follows: 1 ) LDH combined with osteoarthritis, rheumatoid osteoarthritis; (2) LDH combined with malignant tumor; (3) recent history of trauma and surgery; and (4) LDH combined with infections of other organs and systems. And we selected 10 normal people (24-25 years; mean $24.13 \pm 0.85$ years) as the control group.

Four milliliters of blood were extracted with a heparin sodium anticoagulant tube from all the people early in the morning after fasting. Blood samples were sent to the laboratory immediately and centrifuged at $4{ }^{\circ} \mathrm{C}$ at 2,000 $\mathrm{g}$ for 10 minutes. Supernatant was extracted and used for the detection of TNF- $\alpha$.

\section{Primary cell isolation and culture}

All procedures are in compliance with the requirement of Qilu Hospital's Research Ethic Committee, Shandong University, China. All the intervertebral disc tissues were harvest from the lumber spine surgery of the patients with IDD. After washed with sterile phosphate buffer (PBS) 3 times and then removed the endplate cartilage and annulus fibrosus (AF) carefully using a dissecting microscope. The nucleus pulposus (NP) was digested with $0.25 \%$ trypsin (Hyclone, Logan, USA) for 30 minutes and $0.2 \%$ type II collagenenzyme (SigmaAldrich, St. Louis, USA) for 4 hours. Then seeded the NP cell suspension in the $25 \mathrm{~cm}^{2}$ cell culture flask at a density of approximately 25,000 cells $/ \mathrm{cm}^{2}$ in DMEM/F12 culture medium (HyClone, Logan, USA) supplemented with 10\% fetal bovine serum (FBS, Gibco, Waltham, USA), $100 \mathrm{U} /$ $\mathrm{mL}$ penicillin and $100 \mathrm{mg} / \mathrm{mL}$ streptomycin (HyClone, USA) and then incubated in the incubator with $5 \% \mathrm{CO}_{2}$, $37^{\circ} \mathrm{C}$. Replaced the culture medium every 3 days, after the NP cells reached $80-90 \%$ confluence then passaged with $0.25 \%$ trypsin. In this study, we used second or third generation cells for all experiments.

\section{Culture of IVD tissues explants}

The procedure was performed as previously described [42-44]. The human intervertebral disc (IVD) tissues derived from surgical resection of patients with lumbar fracture. After carefully separated the annulus fibrous and endplates under aseptic conditions then cultured in DMEM/F 12 culture medium (HyClone, Logan, USA) supplemented with $10 \%$ fetal bovine serum (FBS, Gibco, Waltham, USA), $100 \mathrm{U} / \mathrm{mL}$ penicillin and $100 \mathrm{mg} / \mathrm{mL}$ streptomycin (HyClone, USA) in the absence of presence of TNF- $\alpha$ (50 ng/ml, Abcam, USA) with or without Atsttrin ( $1 \mu \mathrm{g} / \mathrm{ml}$, Sangon Biotech, China) for $7 \mathrm{~d}$, the medium is replaced every 2 days.

The specimen of mouse spine were taken from the 3-month-old mice, after complete dissected the spine and removed the surrounding soft tissues, cut the lumbar spine into the length of $5 \mathrm{~mm}$ and keep the integrity of the intervertebral disc. Soaked the lumbar spine of the mouse with $100 \mathrm{U} / \mathrm{ml}$ penicillin/streptomycin 30 minutes, then culture the lumbar spine in the medium as described above. For Safranin O/Fast Green staining and HE staining, the explants of lumbar spine of the mouse were fixed in $4 \%$ paraformaldehyde for $48 \mathrm{~h}$ and processed for paraffin embedding. Sections were stained with Modified Safranine O-Fast Green FCF Cartilage Stain Kit (Solarbio, USA) according to the manufacture instruction.

\section{Immunohistochemistry (IHC) and immunofluorescence staining}

Degenerated IVD tissues obtained from the patients with lumber disc herniation, the disc samples were fixed in $4 \%$ formaldehyde and then embedded with paraffin. The paraffin was cut into 4 um sections. After deparaffinized and rehydrated, $0.125 \%$ trypsin (ZSGB-Bio, Beijing, China) was used to antigen repair, then incubated the section with $3 \%$ hydrogen peroxide to eliminate endogenous peroxidase activity. Then use $20 \%$ goat serum (ZSGB-Bio, Beijing, China) to close the nonspecific protein binding sites. The sections were incubated with rabbit anti-human iNOS (1:200, Abcam, USA), rabbit anti-human MMP-13(1:200, Abcam, USA) and rabbit anti-human COX-2 (1:200, Abcam, USA, rabbit antihuman IL-17(1:200, Affinity, USA)) primary antibodies overnight at $4^{\circ} \mathrm{C}$. Then the incubated the sections with a goat anti-rabbit immunoglobulin( $\operatorname{IgG}$ )-horseradish peroxidase (HRP) secondary antibody (1:200, ZSGBBio, China) at $37^{\circ} \mathrm{C}$ for 1 hour. IX71-SIF type microscope (Olympus, Tokyo, Japan) was used to take the images, image-Pro Plus software (Media Cybernetics, Warrendale, USA) was used to quantify the mean densities (MDs) of the expression intensities of all the cytokines.

For immunofluorescence staining The NP cells were treated with $10 \mathrm{ng} / \mathrm{ml}$ of TNF- $\alpha$ (Abcam, USA) in the presence or absence of $200 \mathrm{ng} / \mathrm{ml}$ of Atsttrin (Sangon Biotech, China) for $48 \mathrm{~h}$. Then fixed the cells with $4 \%$ formaldehyde for 10 minutes, and permeabilized in $0.2 \%$ Triton-X 100 for 15 minutes and then blocked in $1 \%$ BSA for 30 minutes at room temperature. Then incubate the cells with rabbit anti-human COX-2 (1:400, Abcam, USA) and rabbit anti-human iNOS (1:400, Abcam, USA) 
primary antibody overnight at $4^{\circ} \mathrm{C}$. The next day cells were washed with PBS and then incubated in a secondary fluorescently labeled goat anti-rabbit immunoglobulin (IgG) antibody (1:200, ZSGB-BIO, China) for 1 hour at room temperature. The image was taken by a fluorescent microscope (Olympus IX51, Japan).

\section{Cell treatment}

To investigate the effects of Atsttrin on TNF- $\alpha$, human NP cells were seeded into a six-well plate and stimulated with TNF- $\alpha(10 \mathrm{ng} / \mathrm{ml})$ with or without Atsttrin $(0,20,50,100,200 \mathrm{ng} / \mathrm{ml}$, Sangon Biotech, China) for 48 hours. Then harvest the NP cells for western blot analysis and real-time PCR (RT-PCR) to observe the expression level of COX-2, MMP-13 and iNOS. The supernatant were harvested for ELISA test of IL-6.

\section{Protein extraction and western blotting}

After the NP cells were confluence in the six-well plate then lysed the cells with RIPA buffer (Millipore, Billerica, MA, USA) on ice for 40 minutes. Then centrifuged at $4{ }^{\circ} \mathrm{C}, 12,000 \mathrm{rpm}$. Carefully absorb the supernatant and measure the protein concentration with BCA protein Assay Kit (Biotechnology Co., Beijing, China) according to the manufacture instructions. Separated each group of protein in 10\% acrylamide-SDSPAGE and subsequently transferred to PVDF membranes (Millipore, USA). Blocked the membranes with TBST which contain 5\% milk powder and followed incubate with primary antibodies (rabbit anti-MMP-13, 1: 1,000, Abcam, USA; rabbit anti-COX-2, 1:1,000, Abcam, USA and rabbit anti-iNOS, 1:1000, Ancam) overnight at $4^{\circ} \mathrm{C}$. Then incubate the PVDF membranes in goat anti-rabbit immunoglobulin (IgG)-horseradish peroxidase (HRP) secondary antibody (1:3000; Beijing Golden Bridge Bioechnology, China) at room temperature for 1 hour. Equal protein loading was confirmed by reprobing the membranes with the rabbit anti-GAPDH-HRP antibody (1:3,000, Proteintech, USA). Protein bands were detected using a FluorChem E Chemiluminescent Western Blot Imaging System (Amersham Imager 600, GE Amersham USA) and image-Pro Plus software (Media Cybernetics, Warrendale, USA) was used to analyze the optical density of each strip [23].

\section{RNA extraction and real-time PCR}

After treated with TNF- $\alpha$ and Atsttrin, the human NP cells were disintegrated with TRIzol reagent (Takara Bio, Japan). After total RNA was extracted then reverse transcribed to cDNA according to the manufacturer's instructions of cDNA Synthesis Kit (GeneCopoeia, Inc. USA). Real-time PCR reactions were carried out on Roche
LightCycler (Roche, USA) utilizing a SYBR Green PCR Matrix Mix (Toyobo, Japan). The nucleotide sequences of MMP-13, COX-2, iNOS and GAPDH primers are listed in Table 1.

\section{Enzyme-linked immunosorbent assay (ELISA)}

We obtained the serum sample from the patients with $\mathrm{LDH}$ and stored at $-20^{\circ} \mathrm{C}$. The supernatants harvested from NP cell culture and stored at $-20^{\circ} \mathrm{C}$ until assay. The serum concentration of TNF- $\alpha$ was measured by ELISA according to the manufacturer's instructions (Abcam, USA), IL-6 in the supernatants from conditioned NP cells cultures were detected utilizing Human IL-6 Elisa kit (BlueGene, China) follow the instructions protocol. The color reaction was assayed at $450 \mathrm{~nm}$ using a Varioskan flash multifunction plate reader (Thermo Fisher Scientific, Waltham, MA).

\section{Statistical analysis}

Statistics were analyzed using SPSS 22.0 (SPSS, Chicago, Illinois, USA), all data were conducted as mean values \pm standard error of mean $(\mathrm{SEM}) . \mathrm{P}<0.05$ was considered as statistically significant.

\section{Abbreviations}

PGRN: progranulin; HE staining: Hematoxylin and Eosin staining; TNF- $\alpha$ : Tumor Necrosis Factor $\alpha$; IL-1 $\beta$ : interleukin-1 $\beta$; IVD: intervertebral disc; MMP13: matrix metalopeptidase 13; COX-2: cyclooxygenase-2; iNOS: inducible nitric oxide synthase; NP: nucleus pulposus; AF: annulus fibrosus.

\section{Author contributions}

Study concept and design: Lei Cheng, Jianlu Wei. Acquisition of data: Hong Ding.

Analysis and interpretation of data: Hong Ding, Jianlu Wei, Yunpeng Zhao, Lian Liu.

Statistical analysis: Yunpeng Zhao, Yi Liu.

Drafting of the manuscript: Hong Ding, Jianlu Wei, Lei Cheng.

\section{CONFLICTS OF INTEREST}

We herein declare that we have no conflicts of interest.

\section{FUNDING}

The work was supported by grants from the National Natural Science Foundation of China (81572191). 


\section{REFERENCES}

1. Arana E, Marti-Bonmati L, Vega M, Bautista D, Molla E, Costa S, Montijano R. Relationship between low back pain, disability, MR imaging findings and health care provider. Skeletal Radiol. 2006; 35: 641-7. http://doi.org/10.1007/ s00256-006-0100-x.

2. Teraguchi M, Yoshimura N, Hashizume H, Muraki S, Yamada H, Minamide A, Oka H, Ishimoto Y, Nagata K, Kagotani R, Takiguchi N, Akune T, Kawaguchi H, et al. Prevalence and distribution of intervertebral disc degeneration over the entire spine in a population-based cohort: the Wakayama Spine Study. Osteoarthritis Cartilage. 2014; 22: 104-10. http://doi.org/10.1016/j.joca.2013.10.019.

3. Williams FM, Sambrook PN. Neck and back pain and intervertebral disc degeneration: role of occupational factors. Best Pract Res Clin Rheumatol. 2011; 25: 69-79. http://doi.org/10.1016/j.berh.2011.01.007.

4. Lai A, Moon A, Purmessur D, Skovrlj B, Laudier DM, Winkelstein BA, Cho SK, Hecht AC, Iatridis JC. Annular puncture with tumor necrosis factor-alpha injection enhances painful behavior with disc degeneration in vivo. Spine J. 2016; 16: 420-31. http://doi.org/10.1016/j. spinee.2015.11.019.

5. Walter BA, Likhitpanichkul M, Illien-Junger S, Roughley PJ, Hecht AC, Iatridis JC. TNFalpha transport induced by dynamic loading alters biomechanics of intact intervertebral discs. PLoS One. 2015; 10: e0118358. http://doi. org/10.1371/journal.pone.0118358.

6. Wang H, Schiltenwolf M, Buchner M. The role of TNFalpha in patients with chronic low back pain-a prospective comparative longitudinal study. Clin J Pain. 2008; 24: 2738. http://doi.org/10.1097/AJP.0b013e31816111d3.

7. Zhao X, Fan W, Xu Z, Chen H, He Y, Yang G, Yang G, Hu H, Tang S, Wang P, Zhang Z, Xu P, Yu M. Inhibiting tumor necrosis factor-alpha diminishes desmoplasia and inflammation to overcome chemoresistance in pancreatic ductal adenocarcinoma. Oncotarget. 2016; 7: 81110-22. http://doi.org/10.18632/oncotarget.13212.

8. Bradley JR. TNF-mediated inflammatory disease. J Pathol. 2008; 214: 149-60. http://doi.org/10.1002/path.2287.

9. He Z, Bateman A. Progranulin (granulin-epithelin precursor, PC-cell-derived growth factor, acrogranin) mediates tissue repair and tumorigenesis. J Mol Med (Berl). 2003; 81: 60012. http://doi.org/10.1007/s00109-003-0474-3.

10. Diaz-Cueto L, Arechavaleta-Velasco F, Diaz-Arizaga A, Dominguez-Lopez P, Robles-Flores M. PKC signaling is involved in the regulation of progranulin (acrogranin/ PC-cell-derived growth factor/granulin-epithelin precursor) protein expression in human ovarian cancer cell lines. Int J Gynecol Cancer. 2012; 22: 945-50. http://doi.org/10.1097/ IGC.0b013e318253499c.

11. Jian J, Konopka J, Liu C. Insights into the role of progranulin in immunity, infection, and inflammation. J Leukoc Biol. 2013; 93: 199-208. http://doi.org/10.1189/jlb.0812429.
12. Tang W, Lu Y, Tian QY, Zhang Y, Guo FJ, Liu GY, Syed NM, Lai Y, Lin EA, Kong L, Su J, Yin F, Ding AH, et al. The growth factor progranulin binds to TNF receptors and is therapeutic against inflammatory arthritis in mice. Science. 2011; 332: 478-84. http://doi.org/10.1126/science.1199214.

13. Xia Q, Zhu S, Wu Y, Wang J, Cai Y, Chen P, Li J, Heng $\mathrm{BC}$, Ouyang HW, Lu P. Intra-articular transplantation of atsttrin-transduced mesenchymal stem cells ameliorate osteoarthritis development. Stem Cells Transl Med. 2015; 4: 523-31. http://doi.org/10.5966/sctm.2014-0200.

14. Liu C, Li XX, Gao W, Liu W, Liu DS. Progranulin-derived Atsttrin directly binds to TNFRSF25 (DR3) and inhibits TNF-like ligand 1A (TL1A) activity. PLoS One. 2014; 9: e92743. http://doi.org/10.1371/journal.pone.0092743.

15. Wang Q, Xia Q, Wu Y, Zhang X, Wen F, Chen X, Zhang S, Heng BC, He Y, Ouyang HW. 3D-printed Atsttrinincorporated alginate/hydroxyapatite scaffold promotes bone defect regeneration with TNF/TNFR signaling involvement. Adv Healthc Mater. 2015; 4: 1701-8. http:// doi.org/10.1002/adhm.201500211.

16. Molinos M, Almeida CR, Caldeira J, Cunha C, Goncalves $\mathrm{RM}$, Barbosa MA. Inflammation in intervertebral disc degeneration and regeneration. J R Soc Interface. 2015; 12 : 20150429. http://doi.org/10.1098/rsif.2015.0429.

17. Le Maitre CL, Freemont AJ, Hoyland JA. The role of interleukin-1 in the pathogenesis of human intervertebral disc degeneration. Arthritis Res Ther. 2005; 7: R732-45. http://doi.org/10.1186/ar1732.

18. Wang J, Markova D, Anderson DG, Zheng Z, Shapiro IM, Risbud MV. TNF-alpha and IL-1beta promote a disintegrinlike and metalloprotease with thrombospondin type I motif5-mediated aggrecan degradation through syndecan-4 in intervertebral disc. J Biol Chem. 2011; 286: 39738-49. http://doi.org/10.1074/jbc.M111.264549.

19. Zhang Y, Liu L, Wang S, Zhao Y, Liu Y, Li J, Nie L, Cheng L. Production of CCL20 on nucleus pulposus cells recruits IL-17-producing cells to degenerated IVD tissues in rat models. J Mol Histol. 2016; 47: 81-9. http://doi. org/10.1007/s10735-015-9651-2.

20. Kim JS, Ellman MB, Yan D, An HS, Kc R, Li X, Chen D, Xiao G, Cs-Szabo G, Hoskin DW, Buechter DD, Van Wijnen AJ, Im HJ. Lactoferricin mediates anti-inflammatory and anti-catabolic effects via inhibition of IL-1 and LPS activity in the intervertebral disc. J Cell Physiol. 2013; 228: 1884-96. http://doi.org/10.1002/jcp.24350.

21. Seguin CA, Pilliar RM, Roughley PJ, Kandel RA. Tumor necrosis factor-alpha modulates matrix production and catabolism in nucleus pulposus tissue. Spine (Phila Pa 1976). 2005; 30: 1940-8.

22. Hu J, Yan Q, Shi C, Tian Y, Cao P, Yuan W. BMSC paracrine activity attenuates interleukin-1beta-induced inflammation and apoptosis in rat AF cells via inhibiting relative NF-kappaB signaling and the mitochondrial pathway. Am J Transl Res. 2017; 9: 79-89. 
23. Zhang Y, Zhao Y, Li J, Wang S, Liu Y, Nie L, Cheng L. Interleukin-9 promotes TNF-alpha and PGE2 release in human degenerated intervertebral disc tissues. Spine (Phila Pa 1976). 2016; 41: 1631-40. http://doi.org/10.1097/ brs.039280R1039280R11621.

24. Jeffcoate WJ, Game F, Cavanagh PR. The role of proinflammatory cytokines in the cause of neuropathic osteoarthropathy (acute Charcot foot) in diabetes. Lancet. 2005; 366: 2058-61. http://doi.org/10.1016/ s0140-6736(05)67029-8.

25. Chen S, Huang Y, Zhou ZJ, Hu ZJ, Wang JY, Xu WB, Fang XQ, Fan SW. Upregulation of tumor necrosis factor alpha and ADAMTS-5, but not ADAMTS-4, in human intervertebral cartilage endplate with modic changes. Spine (Phila Pa 1976). 2014; 39: E817-25. http://doi.org/10.1097/ brs.039280R1039280R10362.

26. Purmessur D, Walter BA, Roughley PJ, Laudier DM, Hecht $\mathrm{AC}$, Iatridis J. A role for TNFalpha in intervertebral disc degeneration: a non-recoverable catabolic shift. Biochem Biophys Res Commun. 2013; 433: 151-6. http://doi. org/10.1016/j.bbrc.2013.02.034.

27. Dudek M, Yang N, Ruckshanthi JP, Williams J, Borysiewicz E, Wang P, Adamson A, Li J, Bateman JF, White MR, BootHandford RP, Hoyland JA, Meng QJ. The intervertebral disc contains intrinsic circadian clocks that are regulated by age and cytokines and linked to degeneration. Ann Rheum Dis. 2017; 76: 576-84. http://doi.org/10.1136/ annrheumdis-2016-209428.

28. Shamji MF, Guha D, Paul D, Shcharinsky A. Systemic inflammatory and Th17 immune activation among patients treated for lumbar radiculopathy exceeds that of patients treated for persistent postoperative neuropathic pain. Neurosurgery. 2017. http://doi.org/10.1093/neuros/nyx052.

29. Genevay S, Stingelin S, Gabay C. Efficacy of etanercept in the treatment of acute, severe sciatica: a pilot study. Ann Rheum Dis. 2004; 63: 1120-3. http://doi.org/10.1136/ ard.2003.016451

30. Zhang W, Nie L, Wang Y, Wang XP, Zhao H, Dongol S, Maharjan S, Cheng L. CCL20 secretion from the nucleus pulposus improves the recruitment of CCR6-expressing Th17 cells to degenerated IVD tissues. PLoS One. 2013; 8: e66286. http://doi.org/10.1371/journal.pone.0066286.

31. Li JK, Nie L, Zhao YP, Zhang YQ, Wang X, Wang SS, Liu Y, Zhao H, Cheng L. IL-17 mediates inflammatory reactions via $\mathrm{p} 38 / \mathrm{c}-\mathrm{Fos}$ and $\mathrm{JNK} / \mathrm{c}-\mathrm{Jun}$ activation in an AP-1-dependent manner in human nucleus pulposus cells. J Transl Med. 2016; 14: 77. http://doi.org/10.1186/ s12967-016-0833-9.

32. Hrabal R, Chen Z, James S, Bennett HP, Ni F. The hairpin stack fold, a novel protein architecture for a new family of protein growth factors. Nat Struct Biol. 1996; 3: 747-52.

33. Zhu J, Nathan C, Jin W, Sim D, Ashcroft GS, Wahl SM, Lacomis L, Erdjument-Bromage H, Tempst P, Wright CD,
Ding A. Conversion of proepithelin to epithelins: roles of SLPI and elastase in host defense and wound repair. Cell. 2002; 111: 867-78.

34. Zhao YP, Liu B, Tian QY, Wei JL, Richbourgh B, Liu CJ. Progranulin protects against osteoarthritis through interacting with TNF-alpha and beta-catenin signalling. Ann Rheum Dis. 2015; 74: 2244-53. http://doi.org/10.1136/ annrheumdis-2014-205779.

35. Liu CJ, Bosch X. Progranulin: a growth factor, a novel TNFR ligand and a drug target. Pharmacol Ther. 2012; 133: 124-32. http://doi.org/10.1016/j.pharmthera.2011.10.003.

36. Liu CJ. Progranulin: a promising therapeutic target for rheumatoid arthritis. FEBS Lett. 2011; 585: 3675-80. http:// doi.org/10.1016/j.febslet.2011.04.065.

37. Sfikakis PP, Tsokos GC. Towards the next generation of anti-TNF drugs. Clin Immunol. 2011; 141: 231-5. http:// doi.org/10.1016/j.clim.2011.09.005.

38. Wei J, Hettinghouse A, Liu C. The role of progranulin in arthritis. Ann N Y Acad Sci. 2016; 1383: 5-20. http://doi. org/10.1111/nyas.13191.

39. Wang H, Ahrens C, Rief W, Gantz S, Schiltenwolf M, Richter W. Influence of depression symptoms on serum tumor necrosis factor-alpha of patients with chronic low back pain. Arthritis Res Ther. 2010; 12: R186. http://doi. org/10.1186/ar3156.

40. Billinghurst RC, Dahlberg L, Ionescu M, Reiner A, Bourne R, Rorabeck C, Mitchell P, Hambor J, Diekmann O, Tschesche H, Chen J, Van Wart H, Poole AR. Enhanced cleavage of type II collagen by collagenases in osteoarthritic articular cartilage. J Clin Invest. 1997; 99: 1534-45. http:// doi.org/10.1172/jci119316.

41. Shukla S, Gupta S. Suppression of constitutive and tumor necrosis factor alpha-induced nuclear factor (NF)-kappaB activation and induction of apoptosis by apigenin in human prostate carcinoma PC-3 cells: correlation with downregulation of NF-kappaB-responsive genes. Clin Cancer Res. 2004; 10: 3169-78.

42. Li Z, Lang G, Karfeld-Sulzer LS, Mader KT, Richards RG, Weber FE, Sammon C, Sacks H, Yayon A, Alini M, Grad S. Heterodimeric BMP-2/7 for nucleus pulposus regeneration-in vitro and ex vivo studies. J Orthop Res. 2017; 35: 51-60. http://doi.org/10.1002/jor.23351.

43. Liu C, Choi H, Johnson ZI, Tian J, Shapiro IM, Risbud MV. Lack of evidence for involvement of TonEBP and hyperosmotic stimulus in induction of autophagy in the nucleus pulposus. Sci Rep. 2017; 7: 4543. http://doi. org/10.1038/s41598-017-04876-2.

44. Ellman MB, Kim JS, An HS, Chen D, Kc R, An J, Dittakavi T, van Wijnen AJ, Cs-Szabo G, Li X, Xiao G, An S, Kim $\mathrm{SG}$, et al. Toll-like receptor adaptor signaling molecule MyD88 on intervertebral disk homeostasis: in vitro, ex vivo studies. Gene. 2012; 505: 283-90. http://doi.org/10.1016/j. gene.2012.06.004. 